\title{
Improving the Management Process through IT\&C for Increasing the Customer Satisfaction Level in Health Care Sector
}

\author{
Darko SHULESKI \\ Monica Adriana PANAIT2 \\ Cătalin Liviu PRICOP3 \\ Elena TALEVSKA ${ }^{4}$
}

\begin{abstract}
In order to become Client-oriented, an organization needs to improve each service and to align the business processes with its customer satisfaction strategy. Customer oriented means to place the client satisfaction at the core of the business decisions. To be customer-oriented means that you need to focus on customers' needs and align them with the company strategy and objectives in order to satisfy clients. According to (Anderson et al., 1997) Customer satisfaction has been one of the top tools for a successful business. Customer satisfaction is defined as an overall evaluation based on the total purchase and consumption experience with the good or service over time. The evolution of Information Technology is accelerating at a very fast pace, organizations need to adopt new methods and already existent information technologies to improve their services, and become a customer oriented company. Business transformation management is a change management strategy, that align the employees, business processes and Information technology with vision and business strategy. Business transformation is the process or results of changing from one state or condition to another. It can be caused by internal or external factors, but the result is a shift in how the organization relates to its wider economic environment. In this article we will try to improve the customer satisfaction level by improving business decision making processes using the mathematical algorithms supported by information and communications technology. In our research we will use the quantitative and qualitative methods and will be applying fuzzy assets in healthcare business services, also using a case study for the Bucharest public health system.
\end{abstract}

KEYWORDS: Transformation Management, Client oriented, Decision making, IT\&C, BI, Fuzzy assets.

JEL CLASSIFICATION: $I 11, M 15, O 33$.

\section{INTRODUCTION}

With the introduction of IT\&C, the business world changed forever. Information and communication technology is used in order to improve the business processes and to ensure that processes are setup and run correctly. Private organizations use IT\&C in almost every department (financial, supply, manufacturing, marketing etc.) to improve the quality of their services. Compared to the private sector, a large number of organizations delivering public services are not technology oriented. The healthcare sector needs to improve their services continuously, and to adopt best practices in order to increase their customer satisfaction level,

\footnotetext{
${ }^{1}$ The Bucharest University of Economic Studies, Romania, darko.shuleski@man.ase.ro

${ }^{2}$ The Bucharest University of Economic Studies, Romania

${ }^{3}$ The Bucharest University of Economic Studies, Romania

${ }^{4}$ The National University of Political Studies and Public Administration, Romania
} 
by using and implementing information technology and communications tools. An important measure with impact in improving the healthcare services is to treat patients as customers. Customer orientation means to offer your clients personalized services. According to (Brown 2002) Customer oriented needs to be seen as a personal attitude which refers to "an employee's tendency or predisposition to meet customer needs in an on-the-job context". Another consideration according to (Saxe 1982) promotes Client orientations as a set of organizational behaviors. In this research, we will try to improve the business processes and increase the customer satisfaction level, by implementation of an Information technology (IT-based) tool for prioritization of the patients using health sector services. To improve customer satisfaction level, public healthcare staff need to make a decision very quickly, and that decision needs to be a correct one. Healthcare institutions should be adopting Information technology software based on mathematical method Fuzzy assets used in decision management system, for improving the decision making process in prioritization the patients in emergency sector.

\section{LITERATURE REVIEW}

\subsection{Customer oriented organizations}

As the financial pressure increases and citizens demand improved quality of healthcare services, $\mathrm{CO}$ (Customer Orientation) becomes one of those concepts gaining a lot of momentum within all public sector organizations, including the healthcare ones. The term $\mathrm{CO}$ means the focus on meeting customers' interests, needs, and expectations, and on delivering appropriate and personalized services (Bruno 2017). From a particular perspective, the public healthcare sector is confronted by a powerful increase in competitiveness as private healthcare providers compete for the same patients (customers) by offering a wide array of services. Thus, the public institutions are forced to take a more practical approach of the $\mathrm{CO}$ concept by increasing their standards and meeting the customers' expectations in terms of efficiency and quality.

While shifting to a customer-focused organization, public healthcare institutions need to develop an entire new approach of the patient, one that is more balanced than before, when it was mostly controlled by the service provider. To our knowledge, there are more studies around the healthcare quality concept than on customer orientation one, the latter being more of a marketing-linked approach than the first, derived from management concepts. In (Crosby 1979), defined quality practice as meeting the requirements of the customer (Four Absolutes of Quality Management). Even if the notion was used at that moment related to two other industries (manufacturing and business), it has become increasingly adopted in other areas as well, due to the fact that it outlines a fundamental concept, that in services, no matter their type, the quality standards are imposed by the customers. Existing research (Amin \& Nasharuddin 2013) indicates that hospital service quality should take into account five dimensions, namely admission, medical service, overall service, discharge and social responsibility. Same study indicate "that the establishment of higher levels of hospital service quality will lead customers to have a high level of satisfaction."

Today, patients are changing their statute, becoming more involved in the actual development and "packaging" of the healthcare services they are provided with. They are no longer passive users and they can choose among a wide array of healthcare providers, not only from the local market but from the international ones as well. The healthcare sector needs to act more as a service industry that traditionally put customer satisfaction on the priority podium as one of the main criteria in loyalization and retention. Organizations are starting to work towards building long-term relationships with their customers like in any other services area, by actively 
involving patients in the delivery of the healthcare services, thus making them more in control of their health.

Patients need to be understood and treated as regular consumers as they:

- Request more control and visibility of their medical status (medical history, treatments, available medication and technologies, financial statements);

- Have the possibility for requesting medical services on their own, not only by doctors' requests;

- Can choose from a plenty of options for medical investigations and advice, both in public and private sector;

- Have the public opinion on their side in demanding a certain degree of proficiency and high quality standards. Social media became a powerful and active tool available to all patients and capable of spreading good and bad news in a very timely manner and with great consequences on the provider's brand image;

- Have the right to access their medical information that needs to be accurate and comprehensive, including from a financial point of view (cost of treatment, health insurance etc.)

Studies within the industry conclude that "patient satisfaction is predicted by factors relating to caring, empathy, reliability and responsiveness." along with "physician conduct, service availability, continuity, confidence, efficiency and outcomes" and some later other dimensions including "core services, customization, professional credibility, competence and communication" (Naidu 2009).

Modern healthcare institutions place customers (patients) as first priority and build an entire organizational culture around this very concept. This organizational culture is essential because it affects the internal customers, namely the employees, those that play a huge role in the way external customers, the patients, are being handled from the reception desk to the post-operatory room. Adequate trainings are needed in order to form customer-oriented employees within medical centers but, unfortunately, in Romania, this is rarely a priority for investment. According to (Rabert 2012), core competencies needed by an organization that intends to enhance its customer satisfaction are: values, education and training, empowerment, standardization of work processes, accountability, measurement, transparency, expert resources and feedback.

\subsection{Change Management}

Nowadays organizations looks to digital transformation to optimize their management processes, the necessity for change management best practices is in the top of the list. Implementing the change management best practices in health care organizations, is necessary to adopt new technology for to improve their processes, to become more efficient, and also to maintain the quality and security of information. Implementation the IT\&C or managing the change in health care services need to be supported by clear based methodology. According to (Courtney, 2018) they identified 6 steps for successfully implementing and coordinating the project for business processes improvement.

1. Clearly define the change and align it to business goals;

2. Determinate the impacts and those affected;

3. Develop a communication strategy;

4. Provide effective training;

5. Implement a support structure;

6. Measure the change. 
Seen as one of the world's largest and fastest-growing industries, the healthcare sector faces the need to fuel its own transformation, towards quality and value, with the help of technology. According to the same recent white paper (Hitachi, 2019), digital transformation in the healthcare industry comes in three waves, making the change from the current state, the transactional focus, to:

- Digital Wave 1: Transaction to Integrated Care

- Digital wave 2: Integrated Care with Empowered Member

- Digital Wave 3: Integrated Care with Science of Prevention and Wellness

In Romania, there is a visible need for the public healthcare industry to rely on those technologies and applications that will enhance the sector's overall efficiency. This means defining, refining and implementing those processes that, with the help of new age technology, will allow a more accurate and fast response with improved connectivity with the customers.

\subsection{BTM (Business Transformation Management)}

As shown in (Axel, 2012) "Transformation is common procedure for most, if not all, organizations. On the one hand, exogenous changes such as sustainability, technological innovations, globalization, economic conditions and the changing nature of the workforce have a profound impact on the way organizations execute business. Business Transformation SAP Methodology as shown in (Figure 1) implies changes in many management disciplines as shown: Meta Management (Leadership, Culture, Values, Communication); Strategy Management (Transformation Direction); Value Management (Transformation Direction); Risk Management (Transformation Direction); Project and Programme Management (Transformation Enablement) Business Process Management (Transformation Enablement); IT Transformation Management (Transformation Enablement); Organisational Change Management (Transformation Enablement); Competence and Training Management (Transformation Enablement).

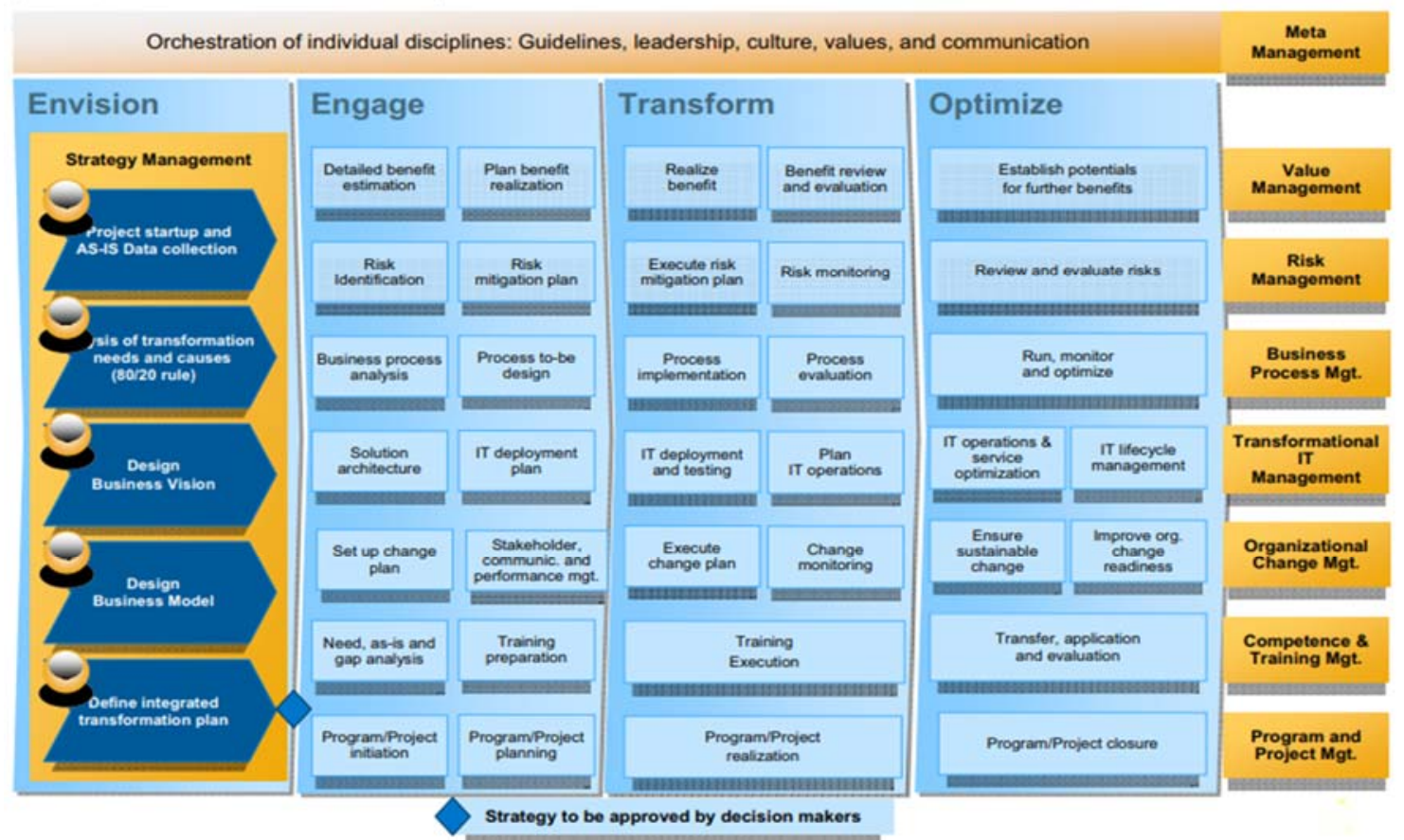

Figure 1. Business Transformation Management Methodology Source: adapted from (Uhl \& Gollenia 2012) 
The ability to lead a business transformation process is important for organizations if they want to improve their competitive advantage. Business transformation management is a complex change of organizational process. An example of business transformation is outsourcing. Only a part of the organizations manage to finish the transformation process successfully. The business transformation process is influenced by many factors, respective: environment, clients or customers, government, etc. The point is that business transformation management means no reinventing management, but instead provides the necessary framework, which can be used for successful organizational transformation and change processes. According to (Uhl \& Gollenia 2012) "Business transformation management is the holistic management of extensive, complex changes on which the organization's future success strongly depends."

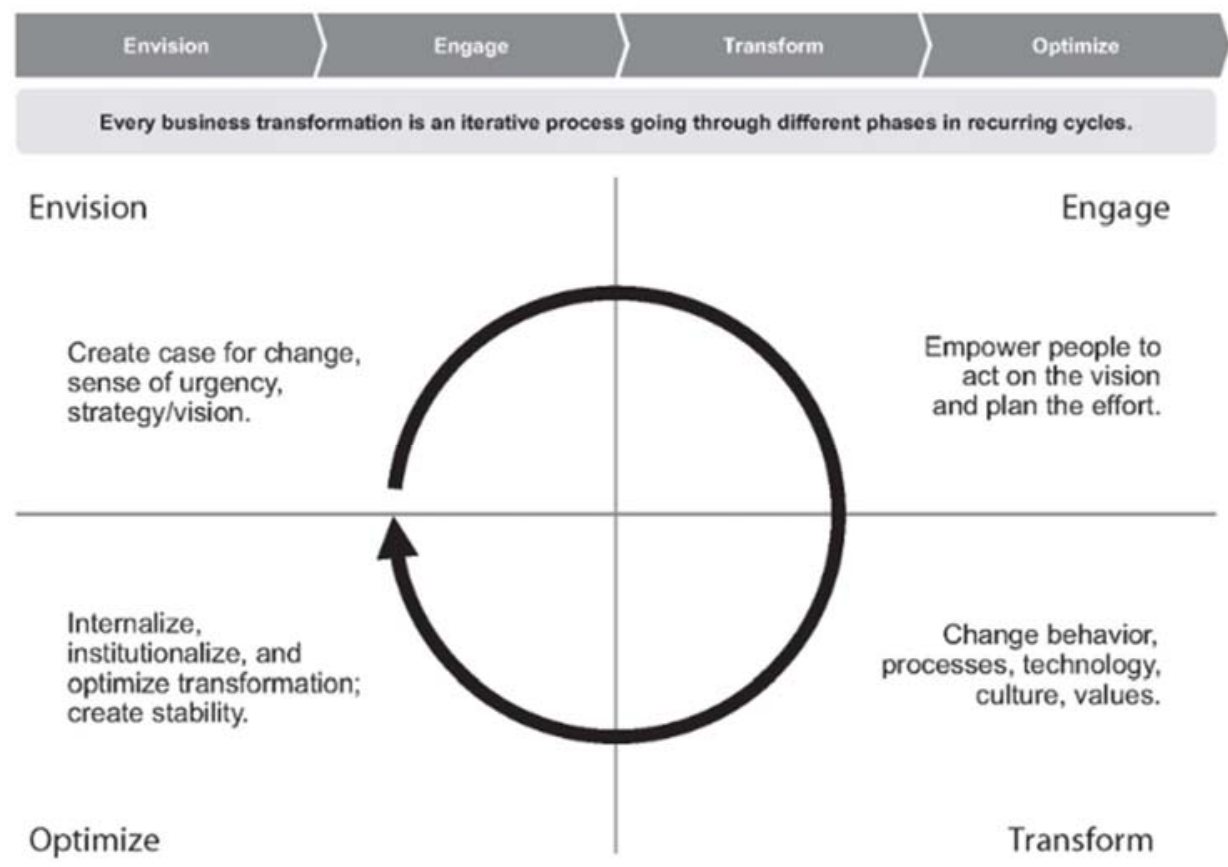

Figure 2. FOUR PHASES OF TRANSFORMATION

Source: adapted from (Llewellyn 2018)

As shown in (Llewellyn 2018) the BTM (Business transformation management methodology, contain four steps or four phases of transformation: (Figure 2)

- Envision;

- Engage;

- Transform;

- Optimize.

In his report, approximately $70 \%$ of the organizations change fail, the reasons being insufficient collaboration, integration, sourcing or project management.

\subsection{Business Intelligence}

Business Intelligence sums up the tools and systems that gather, store, access and analyze corporate data for ultimately helping decision-makers to make better decisions. (Dresner 1993), analyst at Gartner Group, proposed the use of the BI in 1989. Gartner describes Business Intelligence as "the applications, infrastructure and tools and best practices that allow access and analysis of information to improve and optimize decisions and performance."

The concept caught roots in the '70s in the mainframe reporting systems, when reports were 
static, bi-dimensional, and without analytical facilities. The desire and demand for dynamic, multi-dimensional reporting systems with predictive decision support have led to the development of BI, which became the new norm with the emergence of new technologies. The evolution brought by the 1990s period has expanded and improved the BI field, and it is estimated that BI will soon become an important part of the enterprise information system. According to (Moore 2017), the Business Intelligence and Analytics Market at the end of 2020 would increase to $\$ 22.8$ billion. Gartner also says that the BI market continues to expand faster than the global market, reducing traditional IT spending. The modern BI and analytics platform meets the new organizational requirements for accessibility, agility and in-depth knowledge, transferring the market from computerized reporting to agile analysis, including self-service. However, the modern BI and analysis market is expected to slow, from an increase of $63.6 \%$ in 2015 to a $19 \%$ forecast by 2020 . Gartner believes this reflects the fact that data and analyzes are becoming the trend table. The market is rising in terms of room expansion, but price pressure will lower revenue.

Because of the amount and complexity of data used within the healthcare industry, the need of a BI strategy and dedicated tools is becoming more and more obvious, especially in the public sector. BI tools are becoming increasingly critical in the daily operation within the industry, not only focusing on finance controlling and reporting but also on various KPIs (Key Performance Indicators) of the healthcare provider. Additionally, BI tools offer the needed insight to align to regulations while delivering highly profitable services and improving overall patient outcomes. One of the most important role of BI tools, the one of translating data into information, delivers visible benefits to users in healthcare, with direct and positive impact in the life of the patient (for example, BI tools can deliver the best medication scenario to be prescribed to a patient based on medical history and medication exposure so far). This also relates to healthcare providers' scope of improving the customer satisfaction level of its patients.

\subsection{Fuzzy assets}

According to (Lotfi 1965) "A fuzzy set is a class of objects with a continuum of grades of membership. Such a set is characterized by a membership (characteristic) function which assigns to each object a rate of membership ranging between zero and one. The notions of inclusion, union, intersection, complement, relation, convexity, etc., are extended to such sets, and various properties of these notions in the context of fuzzy sets are established."

Fuzzy assets steps

Table 1. Fuzzy method

\begin{tabular}{|c|c|c|}
\hline $\mathrm{Cr}_{\mathrm{ij}}=\frac{\mathrm{Ca}_{\mathrm{ij}}}{\sum_{\mathrm{i}=1}^{\mathrm{n}} \mathrm{Ca}_{\mathrm{ij}}}$ & $\mathrm{Zij}=\frac{\mid \mathrm{cr}_{\mathrm{ij}}-\mathrm{c}_{\mathrm{j}} \mathrm{j}^{\circ}}{\mathrm{c}_{\mathrm{j}}}$ & $f c_{i j}=e^{-k_{j} z_{i j}}$ \\
\hline 2.2 Abraham Wald & 2.2 Bayes-Laplace & 2.3 Leonid Hurwicz \\
\hline Vopt $=\max _{i} \min _{j} F C i j$ & Vopt $=\max \frac{1}{n} \cdot \sum_{j=1}^{n} F C_{i j}$ & Vopt $=\max [\alpha \cdot A i+(1-\alpha) \cdot a i]$ \\
\hline
\end{tabular}

Source: adapted from (Radu et al., 2005) 
The fuzzy method is determining the optimum decision under multi-criteria conditions certainty. Methods in this category are used in decision process of identifying an optimal alternative, when the decider hast to choose from many possible decisional alternative, based on a set of criteria (Table 1).

\section{METHODOLOGY}

This research is based on wide range of sources article in periodical, books and quantitative method questionnaire completed by 71 person which are using the public healthcare services. The data sources used in this paper are an example of data collected from patients benefiting from health sector services in Bucharest, Romania.

\subsection{Research question}

In this research we are trying to fill the knowledge gap, by answering on the research question and three hypotheses as follow: Can we improve the management process and increase the customer satisfaction in healthcare sector by automation the decision-making process?

Hypothesis

1. What are patient satisfaction scores?

2. How can we prioritize the patient, using the IT Tools?

3. Can we increase customer satisfaction in the public sector by prioritizing them by use of BI technologies?

\section{CASE STUDY PUBLIC HEALTHCARE INDUSTRY IN ROMANIA}

The public healthcare industry in Romania is characterized by a generally negative reputation within the public. As characterized by the mass media with many occasions, among the main reasons for this negative image we can count the following: the poor availability of high performant medical services, the incapacity to deliver these services at high quality standards, the lack of medication, international medical procedures, medical competencies and, subsequently, the lack of medical well-trained staff. The priorities of the public medical sector for 2019 cover among others the implementation of 7 screening prevention programs, the communication campaigns run together with UNICEF and WHO and the continuation of initiatives meant to increase customer education on several topics and also the responsibility within the medical staff. There is no obvious and direct initiative targeting customer orientation as the present status needs local public health institutions to cover some other mandatory and urgent issues.

If Romania healthcare institutions intend to improve their statute on the market and their image as well, they need to approach patients as any service provider does nowadays: in a very equitable and customer orientated way, by placing first the needs and expectations of their patients and letting them know they're doing that. This can be translated into specific functions that start to develop within the Romanian healthcare institutions: customer orientation/service, quality assurance, marketing and communication.

One of the subject covered by many conferences and articles worldwide is the one related to how far behind our times is the consumer focus in the healthcare industry, now that the technology stack is here. Observing the Romanian market, we see various stand-alone initiatives with the goal of increasing customer satisfaction, like for example the customer satisfaction forms that are available to patients after a medical investigation, mostly in the private sector and more rarely in the public healthcare institutions. The data is yet to be centralized and researched from a BI perspective, along with the conclusions that would formulate from it. 


\subsection{Survey results and Fuzzy assets example of prioritization the patients in pediatric health sector}

This research had the intent to identify top criteria in customer satisfaction with general pediatric public health services and pediatric public emergency services in Romania. The survey was applied in May 2019 to 71 female respondents with more than 1 child. Over 94\% of them have used the public pediatric healthcare services in the past, rating their overall experience as:

- Very Good (8.5\%);

- Good 36.6\%;

- Fair 31\%;

- $\quad$ Poor $(23.9 \%)$.

In terms of public emergency healthcare services, the overall experience of those respondents that have used this particular type of services, was rated as:

- Excellent $(2.8 \%)$;

- Very Good (7\%);

- Good (29.6\%);

- Fair (21.1\%);

- $\quad$ Poor $(12.7 \%)$

Questionnaire:

Question 1: What are the top three most important aspects the pediatric public healthcare service should improve in order to enhance your overall experience? (Select only 3 )

\section{What are the top three most important aspects the pediatric public healthcare service should improve in order to enhance you overall experience? (Select only 3)}

71 responses

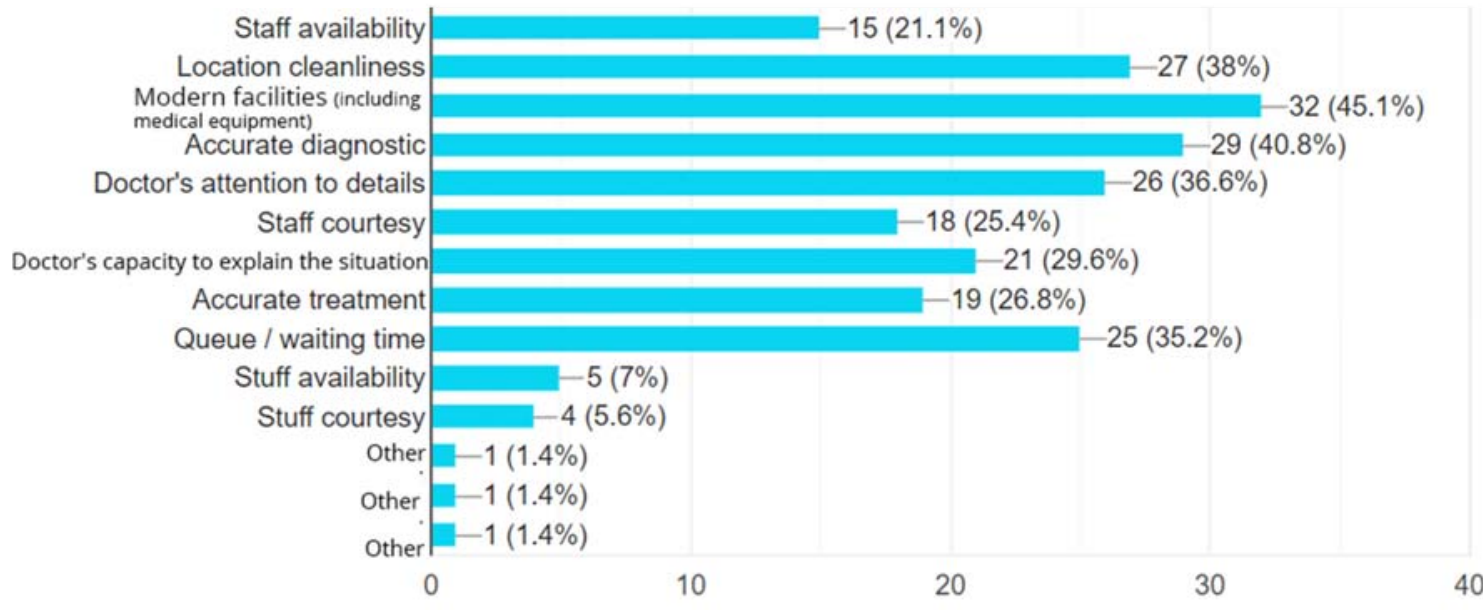

Figure 3. Survey results question no. 1

Source: own research 
The answers indicated that modern facilities, including medical equipment $(45,1 \%)$ is the most important aspect that should be improved by the Romanian public healthcare services in order to enhance the respondents' overall experience. Accurate diagnostic $(40,8 \%)$ and location cleanliness $(38 \%)$ came second and third, thus pointing out the main challenges public healthcare institutions face today (Figure 3).

What are the top three most important aspects the pediatric emergency public healthcare service should improve in order to enhance your overall experience? (Select only 3 )

71 responses

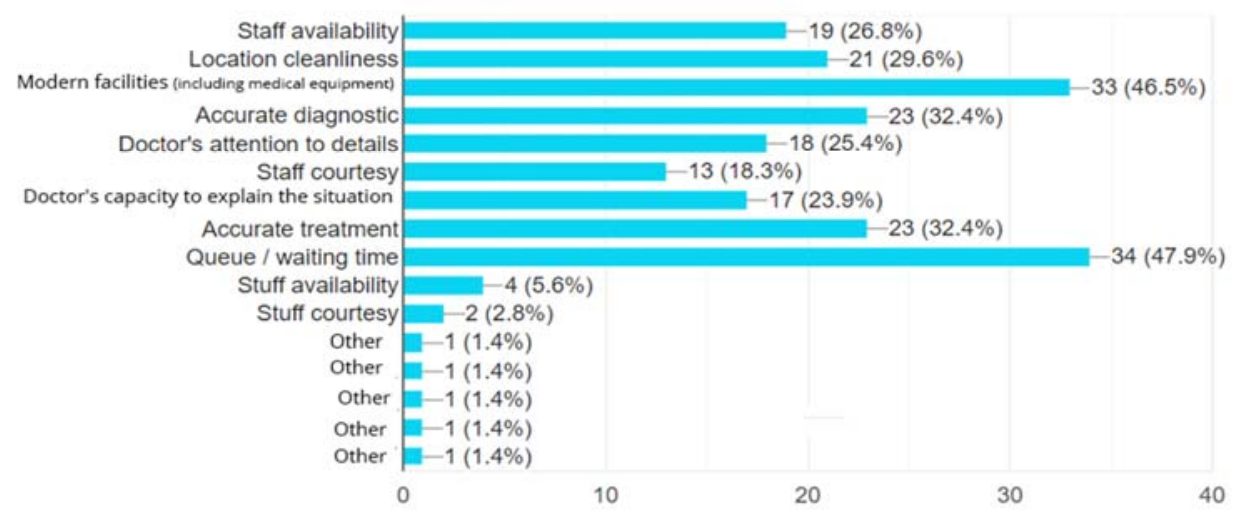

Figure 4. Survey results question no.2 Source: own research

Question no. 2: What are the top three most important aspects the pediatric emergency public healthcare service should improve in order to enhance your overall experience? (Select only 3 ) When referring to the specific emergency pediatric healthcare services in public sector, the respondents selected as top three indicators, the following (figure 4):

- Queue / waiting time ranking first (47.9\%);

- Modern facilities including medical equipment (46.5\%);

- Accurate diagnostic and accurate treatment (32.4\%)

\section{Compared to competitors (private sector), how do you appreciate the} overall pediatric service level?

69 responses

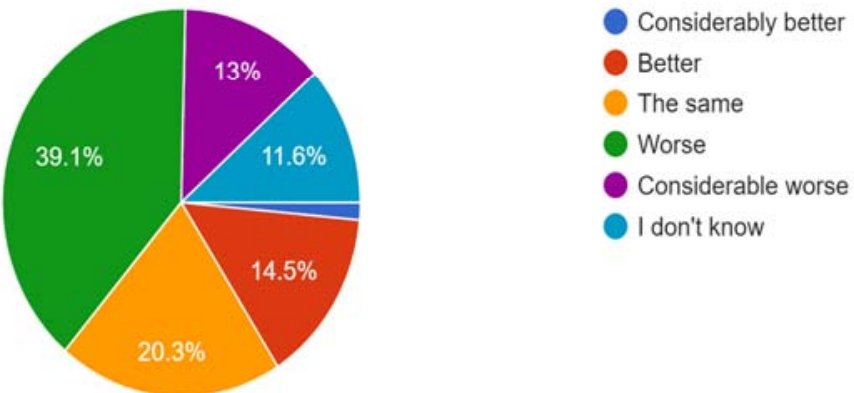

Figure 5. Survey results question no.4

Source: own research

As shown in (Figure 5) 39.1\% of respondents appreciate that public pediatric healthcare services are overall worse than the ones delivered by private institutions and $13 \%$ considerable worse, while $20.3 \%$ consider them at the same level and only $14.5 \%$ better. 
Do you think that installing an automated patients prioritization system would improve your customer satisfaction level?

71 responses

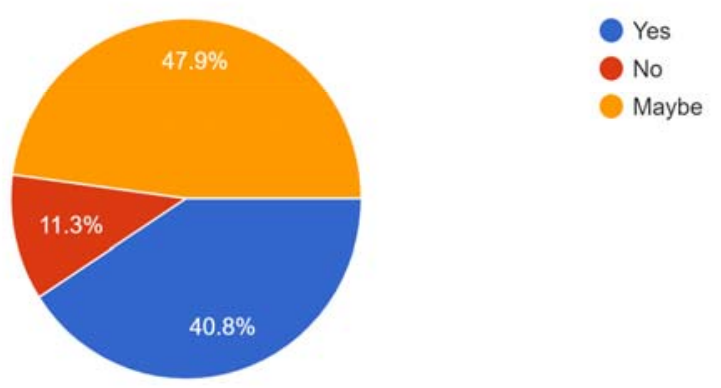

Figure 6. Question no. 4 (survey)

Source: own research

When asked about the installation of a prioritization system for patients, $47,9 \%$ of respondents choose "Maybe" as their answer, while 40.8\% considered that this kind of system would improve their customer satisfaction level. (Figure 6)

How likely are you to recommend general pediatric public health services to a friend?

71 responses

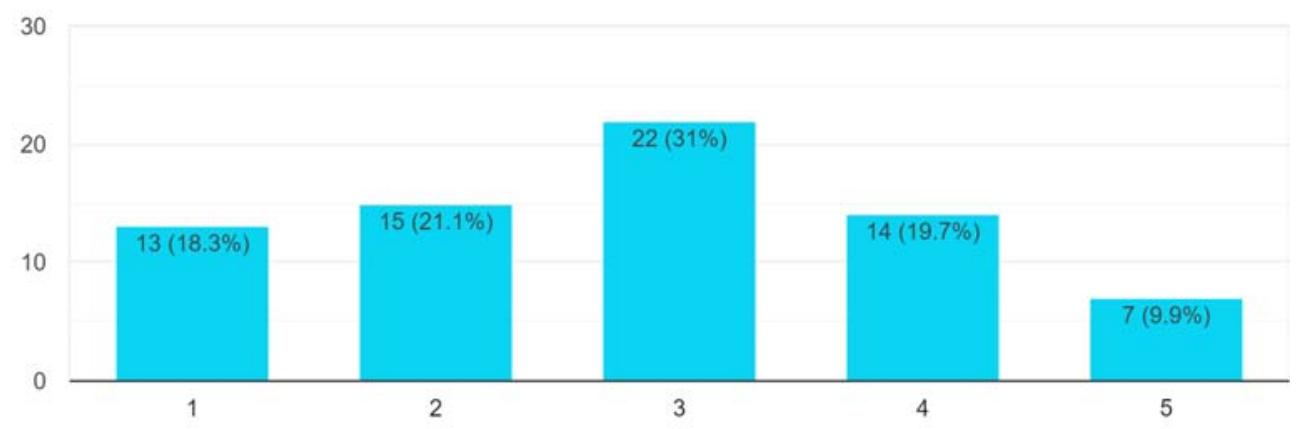

Figure 7. Survey results question no.5

Source: own research

Only $9.9 \%$ of respondents would definitely recommend the general pediatric public health services to a friend while $18.3 \%$ would definitely not recommend it (Figure 7).

How likely are you to recommend pediatric emergency public health

services to a friend?

71 responses

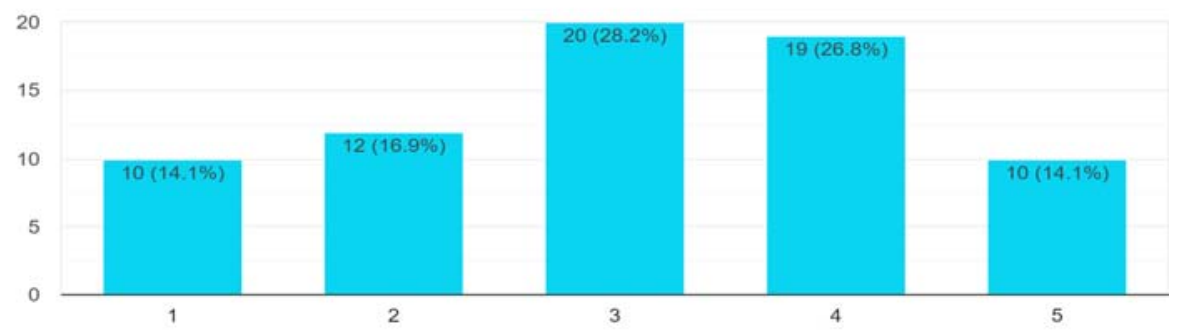

Figure 8. Survey results question no.6

Source: own research 
When coming to the public emergency healthcare services, the number of respondents that would definitely recommend it was equal to the number of those that would definitely not recommend it (14.1\%) Figure 7.

\subsection{Presentation and interpretation of the results and Fuzzy assets example of prioritization the patients in pediatric health sector}

In the case study we use only data to exemplify how to prioritize patients using a mathematical method Fuzzy. (Table 2)

Table 2. Fuzzy method Step 1 (Criteria/posibil variant)

\begin{tabular}{|l|l|l|l|l|l|}
\hline & $\begin{array}{l}\text { Criteria 1 } \\
\text { (age/month)mi } \\
\mathrm{n}\end{array}$ & $\begin{array}{l}\text { Criteria 2 (fever) } \\
(\mathrm{max})\end{array}$ & $\begin{array}{l}\text { Criteria 3 (infectious } \\
\text { disease)min }\end{array}$ & $\begin{array}{l}\text { Criteria 4 } \\
\text { (Vomiting) max }\end{array}$ & $\begin{array}{l}\text { Criteria 5 } \\
\text { (diarrhea) }\end{array}$ \\
\hline Patient 1 & 18 & 37 & YES (10) & 1 & YES (1) \\
\hline Patient 2 & 22 & 39 & NO (20) & 2 & YES(1) \\
\hline Patient 3 & 21 & 37 & YES(10) & 3 & NO(2) \\
\hline Patient 4 & 20 & 38 & NO (20) & 2 & NO(2) \\
\hline Patient 5 & 16 & 36 & YES(10) & 3 & YES $(1)$ \\
\hline
\end{tabular}

Source: Own research

We took an example of 4 patients who need to be prioritize, according to the 5 criteria set out in the table below as shown in (Table 3). We mention that the criteria and the awarding of the coefficient of importance must be analyzed and established together with specialists in this domain.

Table 3. Results from fuzzy method - matrix of characteristic functions

\begin{tabular}{|l|r|r|r|r|r|}
\hline & $\begin{array}{c}\text { C1 } \\
\text { (age/month)min }\end{array}$ & $\begin{array}{c}\text { C2 (fever) } \\
\text { (max) }\end{array}$ & $\begin{array}{c}\text { C3 (infectious } \\
\text { disease)min }\end{array}$ & $\begin{array}{c}\text { C4 (Vomiting) } \\
\text { max }\end{array}$ & $\begin{array}{l}\text { C5 (diarrhea) } \\
\text { min }\end{array}$ \\
\hline Patient 1 & 1.0000 & 0.7699 & 1.0000 & 0.0357 & 1.0000 \\
\hline Patient 2 & 0.2756 & 1.0000 & 0.0033 & 0.1889 & 1.0000 \\
\hline Patient 3 & 0.3803 & 0.7699 & 1.0000 & 1.0000 & 0.0041 \\
\hline Patient 4 & 0.5250 & 0.8774 & 0.0033 & 0.1889 & 0.0041 \\
\hline
\end{tabular}

According to the results of fuzzy assets using the three techniques Pessimist, Bazes- Laplace and Hurwicz the optimal variant is prioritizing Patient 1 as shown in table 4 below. 
Table 4. Results from fuzzy assets application using 3 techniques for decision selection

\begin{tabular}{|c|c|c|}
\hline Pessimist & Bazes-Laplace & HURWICZ \\
\hline Patient 1 & Patient 1 & Patient 1 \\
\hline Patient 3 & Patient 3 & Patient 3 \\
\hline Patient 2 & Patient 2 & Patient 2 \\
\hline Patient 4 & Patient 4 & Patient 4 \\
\hline
\end{tabular}

Source: Own research

After the calculations we concluded that the prioritization of the patients will be in the order presented above. It is easy to make a decision when you have 2 patients and you can prioritize them very easy, but it is a great challenge and a problem we can say, to make the right decision when you have 100 patients and more, when you must prioritize them according to the criteria that are established together with specialists in the field. In that way it's impossible to make the decision if you don't use Information technology.

We will try to test the research hypotheses and to answer to the research question:

Can we improve the management process and increase the customer satisfaction in health care sector by automation the decision making process?

Hypothesis

$\mathrm{H}: 1 . \quad$ What are patient satisfaction scores?

Results coming from the survey highline the reality that the majority of the respondents have identified as top criteria capable of enhancing their experience the same indicators that are publicly discussed and referred to as "hot areas" for improvement. Therefore, we can assume that patients have the same needs for public healthcare investments as the ones proposed by medical authorities, hospital governance, public mass media. The criteria of modern facilities, including medical equipment, ranked first, highlighting one of the most burning issue of the public healthcare institutions, often criticized for the lack of adequate technologies and equipment's. This is one criteria that has almost the same importance in emergency room as within general pediatric services, according to our respondents. Some of other top indicators, like queue / waiting time, for example, can be definitely improved by an IT-based patients prioritization system, especially in the emergency room.

When asked about how this kind of system would improve their customer satisfaction level, while $40.8 \%$ agreed with the idea, $47.9 \%$ would remain uncertain, declaring as "maybe". We appreciate this to be a natural response coming from patients that have not experienced so far the benefits of such a system. This impose that installation should be followed by a strong educational campaign targeting the patients and the medical staff as well.

H:2 How can we prioritize the patient, using the IT Tools? As we could see in the example above, using the Fuzzy Method we found out which of the 4 patients would be the most urgent to be taken care of and also which would be the order of prioritizing the rest. By using such a method through a BI system the medical staff would have a great support on doing a better job and getting better results by prioritizing patients and making sure the relevant support is given in time. The prioritizing system can be changed accordingly to the needs as each medical facility can have a specialist assign the importance of each criteria based on the facility's medical equipment and personnel. 
$\mathrm{H}: 3$ Can we increase customer satisfaction in the public sector by prioritizing them by use of BI technologies? Analyzing the specialized bibliography articles, books, and case studies approached in the field of IT\&C sector and also our professional experience in IT systems management, and analyzing questionnaire-based research, we conclude that the public healthcare service sector requires an IT tool that will help decision-making process in real time. We assess that, with the prioritization of patients in the pediatric sector in Romania, we could improve the decision making process by making decisions using an instrument IT - Business Intelligence, based on fuzzy mathematical algorithm.

\section{CONCLUSIONS}

Nowadays, the Information and communications technology provides the most needed tools organizations need for creating a competitive advantage. Looking for instruments or IT tools to improve their services, public healthcare organizations can adopt the right strategy for change and transformation management like we've described above, alongside with the IT tools for improving their process. All of these will allow them to improve the management process and also the decision making process. The decision-making process for patient prioritization in the pediatric department is a very difficult one and the decision taken by the employees working in customer services will not always be correct, thus imposing the use of a modern IT tool that they can rely on.

Following the research hypothesis mentioned in the paper, we have developed the questions inserted in the questionnaire leading to the following results: In our research based on questionnaire, we have identified that $88.7 \%$ of respondents were either agreeing or neutral to the idea of implementing a system for prioritizing patients, allowing the assumption that this tool could prove beneficial for the public healthcare institutions (Figure 6).

As shown above (in Figure 4) a total of $49.7 \%$ of respondents considered that the most important factor in improving customer satisfaction level is the waiting time in queues. After analyzing the results, we tried to answer our research question: We could partly improve the decisional management process in public sector services and also we could increase the customer satisfaction score. We propose improving decision-making process for patient prioritization by implementing the Business Intelligence using mathematical algorithms, like fuzzy method, to improve the customer satisfaction in Romanian public health care sector.

A Business Intelligence (BI) system allows an enterprise to take better and smarter decisions by relying on collected and processed data and by taking advantage of the automated analysis. Considering how the automated reporting and analysis systems help a business, we believe that implementing BI solutions could allow any medical facility to have a substantial advantage in prioritizing patients and offering timely support to the most needing patients.

\section{REFERENCES}

Amin, M., \& Nasharuddin, S. Z. (2013, 07). Hospital service quality and its effects on patient satisfaction and behavioural intention. Clinical Governance: An International Journal, 18(3), 238-254. doi:10.1108/cgij-05-2012-0016

Anderson, E. W., Fornell, C., \& Rust, R. T. (1997). Customer satisfaction, productivity, and profitability: Differences between goods and services. Marketing science, 16(2), 129145.

Bruno, A., Dell'Aversana, G., \& Zunino, A. (2017, 11). Customer Orientation and Leadership 
in the Health Service Sector: The Role of Workplace Social Support. Frontiers in Psychology, 8. doi:10.3389/fpsyg.2017.01920

Brown, T.J., Mowen, J.C., Donavan, D.T., \& Licata, J.W. (2002). The customer orientation ofservice workers: personality trait effects on self- and supervisor performance ratings. Journal of Marketing Research, 39(1), 110-119.

Courtney, F. (2017). 6 Steps to Effective Organizational Change Management. Retrieved April 15, 2019, from https://www.pulselearning.com/blog/6-steps-effective-organizationalchange-management/

Dresner, H. (1993). Multidimensionality: Ready or not, here it comes ; Office Information Systems Research Note, file: Technology, T-MD-1137. The Gartner Group.

Fornell, C. (2004). American Customer Satisfaction Index, 1994. ICPSR Data Holdings. doi:10.3886/icpsr03973

Lotfi A. Zadeh (1965, 06). Fuzzy sets. Information and Control, 8(3), 338-353. doi:10.1016/s0019-9958(65)90241-x

Llewellyn, H. R. (2018, December 03). Business Transformation Management Methodology. Retrieved May 12, 2019, from https://robllewellyn.com/business-transformationmanagement-methodology/

Moore, S. (n.d.). Gartner Says Worldwide Business Intelligence and Analytics Market to Reach $\$ 18.3$ Billion in 2017. Retrieved May 15, 2019, from https://www.gartner.com/en/ newsroom/press-releases/2017-02-17-gartner-says-worldwide-business-intelligenceand-analytics-market-to-reach-18-billion-in-2017

Naidu, A. (2009). Factors affecting patient satisfaction and healthcare quality. International Journal of Health Care Quality Assurance, 22(4), 366-381. doi:10.1108/ 09526860910964834

Rabert, A. (n.d.). American Nurse Today official Journal of the American Nurses Association (ANA). Retrieved May 11, 2019, from https://www.americannursetoday.com/

Radu, I., Ursăcescu, M., \& Vlădeanu, D. (2005). Informatică şi management: $O$ cale spre performanţă. Editura Universitară.

Saxe, R., \& Weitz, B. A. (1982, 08). The SOCO Scale: A Measure of the Customer Orientation of Salespeople. Journal of Marketing Research, 19(3), 343. doi:10.2307/3151568

Uhl, A., \& Gollenia, L. A. (2016). A Handbook of Business Transformation Management Methodology. London: Taylor and Francis. 